\title{
Notes from experience in application of interactive teaching methods in university settings
}

\author{
Jasmina Arsenijević ${ }^{1}$, Marija Nikolić $^{2}$ and Alla Belousova, ${ }^{3, *}$ \\ ${ }^{1}$ Preschool Teacher Training College in Kikinda, Serbia \\ ${ }^{2}$ University of Belgrade, Serbia \\ ${ }^{3}$ Pedagogy and Defectology, Don State Technical University, Rostov-on-Don
}

\begin{abstract}
Both theory and practise agree that, in order to achieve numerous advantages of interactive teaching, it is crucial that teachers and students have experience in interactive work and posses some social competencies. Interactive teaching are ineffective when teachers lack pedagogical knowledge and experiences and when students unaccustomed to interaction in class. That is why this paper presents the most important experiences in interactive teaching practise in a university environment, shows examples of good practice and points out the most common challenges that teachers may face. Teaching techniques that enable a smooth flow of interaction and enable better effects in the field of learning are offered. The paper recommends techniques of "breaking the ice", building trust, and the gradual introduction of interaction from working in pairs, from smaller to larger groups. The paper further recommends student grouping techniques, which serve as a mechanism for improving the quality of interaction and finally present ideas and experiences for guiding simulations and role plays as one of the most effective interactive methods.
\end{abstract}

\section{Introduction}

The sociological theory of knowledge developed in pedagogy in the late 1960s, whose representatives were Berger and Luckmann (1966) [3] resulted in a major shift in understanding the learning process and, consequently, in understanding the educational process. The constructivist paradigm emerges instead of the traditional learning paradigm: the active and social construction of knowledge replaces knowledge transmission, and the development of personal responsibility, initiative and proactivity becomes main characteristics of educational process. Cognitive and social constructivism, which constitute the new educational paradigm, emphasize the development of knowledge and skills through research, experimentation and collaborative problem solving. In that sense, knowledge is considered primarily as a social product, and the creation of knowledge as a social, rather than an individual act $[1,13,2,7]$.

\footnotetext{
*Corresponding author: belousovaak@gmail.com
} 
Interactive teaching is considered to be the educational process tailored to suit the new educational paradigm. Its social dimension (the meaning of the word "inter") is manifested through cooperation, discussion, debate, teamwork, controversy, etc. Those who learn broader their perspectives through exchanging ideas, experiences and knowledge, the subject of learning is therefore observed and processed from far more angles than in the case of frontal teaching, and knowledge is not adopted, but "built", or rather, "co-built". The active dimension (meaning of the part of the word "active"), which starts from cognitive constructivism, is operationalized through experiments, research, simulations, projects, etc. Those who learn by doing gain real experiences and actively examine and reexamine the subject of learning, and in this process the knowledge is "constructed". Interactive teaching thus combines the active and social aspects of learning, taking advantage of both of these approaches, encouraging the co-construction of knowledge. The emphasis is on those who learn and the way they learn, instead on the teacher and the way he or she transfers knowledge [21].

While there are many examples of the application of interactive methods in educational (and even university) practice, there is still a long way to go before it can be fully and successfully applied. Universities are even more traditionally oriented than elementary or high schools, as frontal teaching is deeply rooted in its practice. $[6,19,12]$. Reliance on the ex-cathedra teaching approach and the unwillingness of a significant proportion of teaching staff to apply innovations in teaching are frequent stumbling blocks in this process at universities. Focused primarily on scientific research, university professors often do not gain enough pedagogical knowledge and experience to change their own teaching practice. On the other hand, the success of interactive teaching also depends on students' motivation and openness to participation, as well as experience in interaction teaching practice.

The subject of this paper is experience in the application of interactive teaching methods in university practice. The paper presents examples of good practice, summarizes the problems that university teachers may face when organizing interactive classes, and offers potential solutions. The information presented in this paper can therefore be of importance to all theorists and practitioners of (higher) education, as well as to those involved in education planning and improvement. The paper can be especially beneficial to university teachers who are looking for practical instructions for interactive teaching.

\section{Review of selected interactive teaching methods}

\subsection{Initial activities}

Each interactive teaching method implies cooperative work of students. The cooperation can be within one pair, a smaller or larger group of students, as well as the whole group, and may be between these categories. It is important to establish a good basis for cooperation at the course beginning with new students. Difficulties can often arise at this stage, especially while working with non-homogenized (When, for example, students from different study years or departments form a joint group on some course) groups of students or groups of students who are not used to interactive forms of teaching.

Working in pairs is common among university students when preparing seminars, miniprojects, presentations etc. It can therefore be a great initial practice for interaction. Enabling students to choose colleague can be very productive in the beginning. This will make it easier for them to take the initial step towards cooperation. However, if students always choose the same colleagues, it is necessary to change the approach, as it can jeopardize the quality of interaction in a group as a whole. In this case, the teacher can 
introduce special criteria for forming pairs. A system of intentional combining different groups is also recommended, as it leads to better cohesion.

When participants gain enough experience to work in pairs, they can move on to more complex interaction in small groups, and later on to even more complex work of intergroup interactions or work on a projects.

\subsection{Encouraging interaction}

The quality and effectiveness of interaction are largely determined by the motivation and competencies of teachers and students. Providing that the teacher possesses pedagogical competence, motivation and time to invest in organizing interactive teaching, it is up to students to cooperate and participate in it. Students are usually willing to agree to all innovations in teaching, whenever they diverge from ex-cathedra approach and present more dynamic and interesting model of learning.

It often happens, however, that there are students who have certain hesitations regarding participation in interactive teaching. Some of these students may affect the course of the class by reluctance or even resistance. Experience shows that, most often, these students did not have enough opportunity to get used to interaction during their previous education. In theory, this phenomenon is known as poor uncertainty management [16]. It arises as a result of a too autocratic upbringing in the family and school, when students perceive insecurity caused by confrontation with the reactions and opinions of other people as a danger, rather than a challenge [10].

In order to overcome this problem, it is necessary to pay special attention to activities that "break the ice", i.e. that develop a sense of trust and belonging, create a good mood and raise energy in the group. At the beginning of working with a new group, it is advisable to organize activities that aim to get to know each other. These activities should not be labourintensive and should not consume much of class time, and can often be used between demanding segments of class, when the group's energy declines. For example, students could be required to find others who have a given common characteristic (such as colour of eyes or favourite type of music). The task for building confidence can be to make a common, meaningful drawing without mutual agreement and communication, using only basic geometric shapes (triangle, square, circle, rectangle) and drawing in shifts. This activity allows students to directly experience interdependence and understand the extent to which collaboration play a part in defining work outcomes. After building trust in the group, it is possible to move on to more demanding interaction and connect them with the class subject. Pantomime and association games can be very effective in this regard.

If within the group who is accustomed and willing to participate in interaction join some students who resist interaction, it is advisable that they are given a less challenging task, such as reading and identifying key items in the selected text. Experience has shown that those students, if interactive work in groups proves to be interesting, will join interaction in the following classes. It is also very effective that students who are not inclined to interact involve as an observers, reporters or possibly members of the jury, while other students are working in groups.

\subsection{Forming groups or teams of students}

Organizing interactive student work in the classroom requires careful preparation of grouping strategy, grouping materials and the identification of responsibilities for students and teacher. There are a number of recommendations for forming a group or a team of students in a simple way. One recommendation is to take a familiar and simple criterion, such as zodiac sign as the basis for forming a group or team. As criteria determine the 
number of groups of students, and therefore the number of students in groups, a caution is needed when planning group interaction. If, for example, the zodiac sign is taken as a division criterion, students will be divided into 12 groups, which can be very demanding for coordination. Ideally, the distribution of students by month of birth will lead to formation of groups with equal number of students. It happens much more often that groups are formed with unequal size. In that case, there are two options: to work with such groups, which can harm realisation of lesson plan, or equalizing number of students in groups, which can lead to losing the meaning of the division itself.

A more reliable method is to take a certain key as the basis for grouping, which enables the formation of groups with size that is more suitable for class. If students are unaccustomed to interaction in teaching process, it is recommended to take simple criteria, such as basic mathematical task (The most practical way is to make cards of the same size, where, for example, the number 100 is written on one card and $20 \times 5$ on the other, $10^{2}$ and 200/2 etc.), plants and animals (On one group of card are written certain plants, on the others type of trees, flowers, cereals, fruits, etc.) or certain shapes (The group consists of students who receive cards with the same shapes written on them). When working with students who have not had previous experience with grouping, there is a high probability that the division process itself will be sufficiently demanding and that additional instructions will be needed.

When students are accustomed to this way of grouping, the division can become more demanding. If time allows and students have some prior knowledge, the material from the teaching subject can be used to form a group. For example, third- and fourth-year students at the Faculty of Agriculture are routinely divided based on the type of oilseeds, stone fruits, or legumes.

If the task given to groups or teams is relatively simple, the division process can be an opportunity to check if students have gained required knowledge. In that case, the key for grouping can be the classification of knowledge from the previous classes. Such a process will require certain knowledge from students, it will take more class time, it is possible that teacher assistance will be needed and it will require control. It is recommended that the teacher assess the students' capacity for this kind of grouping, and modify it with the upcoming task for groups. Otherwise, the grouping process can be over stimulating, and the focus can shift from the aim of the class to the division process.

It is recommended that the material be made in such a way as to enable the formation of groups with five students. The material prepared in this way can be corrected relatively easily by withdrawing one or two cards, i.e. used to form a group with four or three students. It is also important to count students in advance in order to prepare sufficient number of cards.

The total number of students and the required number and size of groups must be taken into account. The number of groups varies according to the criteria, and intergroup interaction (for example, quizzes or competitions) is more demanding in the case of a larger number of groups. The number of students in a group should also be planned in accordance with their assignments, since large groups have different dynamics than smaller ones. If a strict number of students in a group is needed for a certain reason, it should be taken into account that it often happens that the remaining group has a smaller number than the others (When dividing, say, 23 students into groups of five students, four groups of five students and one of three will be obtained), due to the indivisibility of the total number of students to the number of groups. Therefore, it is necessary to anticipate the tasks that the remaining student (or students) will perform. These tasks can be observation, control, reporting etc. 


\subsection{Homogenization versus heterogenization of groups}

An experienced teacher should recognize when it is necessary to introduce additional criteria for grouping instead of allowing student to choose colleagues on their own, as to encourage combination of existing groups of students. As a deliberate crossing of several different groups, we can discuss an example of an elective course called Contemporary teaching methods. The group on this course was created from students from different departments: Psychology, Preschool Teacher, English Teacher and German Language Teacher. Due to the excessive focus of students on colleagues from the same study program, the teacher introduced group combining in order to enhance interaction within students from different study program. Within each group of students from each study program, students were given cards with the names of countries from different continents. The first task was to form teams bringing together countries on the same continent, which led to combination of groups (which brought together students from four study program), followed by the assignment of case study from pedagogical practice. After only one class, there was a greater openness of students and more direct communication between students of different study programs.

Careful grouping of students is important not only to direct interaction, but also to achieve the effectiveness of knowledge building and exchange and flow of the ideas. Namely, neither complete homogenization nor excessive heterogeneity of groups is desirable. While very efficient solutions can be found in very homogeneous groups, there is always a danger of unanimity and uniformity. Heterogeneous groups enable a greater wealth of ideas and more creative solutions to problems, but they are more demanding to lead and it is possible that certain steps in the learning process are missed [10].

When bridging the potential gap of students' inexperience or hesitation, diversity can result in more effective learning. For example, in the course Contemporary teaching methods, creative assignments such as designing new games for children with given pedagogical characteristics, were more successfully realized by interdisciplinary teams. In addition to using pre-existing differences in perspectives, different perspectives can be further encouraged to enhance learning and problem solving. This could be achieved in the most effective way through role-playing and simulation.

\subsection{Simulations and role plays}

One interactive practise on the course Curriculum Development can be given as an example of a simulation method. After initial grouping into teams (Grouping in the examples presented in this part of the paper should always be relatively easy, since students are expected to do demanding tasks during the class), students are given the assignment to discuss the possibilities of connecting the work of primary school and art gallery from the local community. Each student draws a card which gives him or her certain role to interpret: a parent, a school pedagogue, a school principal, an art teacher, a teacher of other subjects or a child. Each team is made up of all these roles. The task of the team is to come up with ideas for the operationalization of school-art gallery cooperation projects, meeting the stated requirements of individual roles. After joint preparation, the teams demonstrate their work, summarizing the projects, the course of the discussion and problems they occur in reaching an agreement, as well as the way in which they resolved them. In this way, possible situations from professional practice are viewed from several angles through simulation, and students better understand these situations by taking specific, separate roles.

An example of the role play could be found in classes of communication. Different forms of communication are studied within one course in the final year of the Faculty of Agriculture. Students are divided into teams of four during this interactive class, and each 
team preform two types of activities. The first activity is pantomime and refers to nonverbal communication. All students in the team draw a card with written emotions. Their task is to express the feeling written on the card to other team members through gesticulation, body language and facial expression. Students rotate so that all members have the opportunity to express given feelings. The first part of the activity is realized within teams, while all teams work in parallel. In the second part of the class, students are expected to present a situation in which, for whatever reason, the communication process was not successful. Teams play a conversation in front of other students. After this ensues discussion in which the teams exchange experiences under the guidance of the teacher and conclusions are made.

Role-playing games, pantomimes, simulations and similar teaching techniques are generally well received by students, and are extremely effective for learning. However, it has been noticed that the quality of work varies from year to year. It is worth noting that these teaching units take place for many years in the same way, under the guidance of the same teacher, so the variations in success depend almost entirely on the abilities and preferences of the students. In some years, students gladly participate in these simulations, after which live discussions develop. Some groups act the situations and then initiate a discussion with their colleagues to check if they understood their demonstration, while others show unwillingness to accomplish this task, or just read the text they prepared. Once, a team at the Faculty of Agriculture refused to perform, preparing only the written script and submitting it without performing or discussing.

The presented examples indicate that students who have experience in innovative teaching methods can be expected to have significant learning outcomes, but also that the teacher should be prepared that the class may not be fully carried out in the way he or she imagined. On the contrary, the teacher should be flexible and not insist on implementing a predefined plan. By carefully and gradually increasing the interaction, the teacher can train students who are not initially ready to interact. That should reduce the possibility that the efforts invested in preparing the class are failed due to the unwillingness of the students to participate in it. If the students mastered the material, the class can be considered successful, even if some actions did not went according to the plan.

Students of one generation within the same department generally build common rules and standards and act as one whole by their final year. From time to time, it happens that one generation is extremely rigid and finds it especially difficult to accept innovations in teaching. It is really a great privilege to watch how students of such generation gradually begin to participate in teaching, ask questions, and later to participate in polemics and other activities without any hesitation. One example vividly describes what changes can occur in working with such students. At the end of the sixth semester (after a whole academic year of cooperation), the students of the Faculty of Agriculture participate in a class of recognizing the food products based on all the senses except the eyesight. The teacher brings a large number of products and the necessary accompanying material in an opaque bag, so the students do not know what is suppose to happen in this class. Students are then asked to volunteer to conduct the class activity without giving instructions how the activity will be implemented. Every year, without exception, even in the generations that initially showed great resistance, large number of students is prepared to participate in the activities on this class. The high degree of trust and interest represent a significant compensation to the teacher for all the effort and activities in improving the teaching methods.

\section{Conclusion}

The paper presents the most significant observations in conducting interactive teaching in a university environment that have been reached through experience, shows examples of 
good practice and points out the most common challenges that teachers may face. Solutions to possible challenges are offered in the form of teaching techniques that enable a smooth flow of interaction and enable better effects in the field of learning. Scientific knowledge was consulted in order to better understand and explain these phenomena, challenges and potential problems and to see possible solutions in the implementation of interactive teaching methods.

There are numerous testimonies in the literature that interactive learning provides extremely positive effects on learning. Research on the results of interactive learning on student results show that interaction enables higher achievements, better memory, better understanding and critical thinking, greater motivation and develop more positive attitudes towards learning than students who learn individually $[5,11,12,14,15,17,18,20]$. In order to achieve the mentioned advantages of interactive teaching in practice, the practical experience of the authors of this paper, as well as the results of numerous research practices and theoretical knowledge show that it is crucial that teachers and students have experience in interactive work and social competencies $[4,9,8]$. The challenges that teachers face are far greater if their initial education and professional development did not prepare them for that [9].

In addition to teacher competencies, the most common cause of problems in interactive work is the lack of student practice. Students lacking practise in interaction are unable to manage in situations that require interdependence, cooperation, interaction and public presentation of results, so that teaching process is often disabled. In this way, the learning process is made more difficult and more time and energy is spent on learning to learn (interact) than on interactive content processing.

In the case of working with students who have no experience with interactive teaching methods, the paper recommends techniques of "breaking the ice" and building trust, and the gradual introduction of interaction from working in pairs, through smaller, to larger groups. The paper further recommends student grouping techniques, which serve as a mechanism for improving the quality and intensity of interaction and finally present ideas and experiences for conducting simulations and role plays as one of the most effective interactive methods. This paper represents an important step towards sharing practical knowledge, ideas and experiences in the higher education community, summarizing experiences and making recommendations for improving practice.

\section{References}

1. J. Arsenijević, Zbornik Visoke škole strukovnih studija za obrazovanje vaspitača u Kikindi 2(10), 9-20 (2015)

2. A. Belousova, L. Abrosimova, M. Bogdanova, INTED Proceedings, 1915-1921 (Valencia, 2017) https://apps.webofknowledge.com/InboundService.do?product $=$ WOS $\&$ Func $=$ Frame $\&$ DestFail $=\mathrm{http} \% 3 \mathrm{~A} \% 2 \mathrm{~F} \% 2 \mathrm{Fwww}$. webofknowledge.com $\&$ SrcA $\mathrm{pp}=\mathrm{RRC} \&$ locale $=\mathrm{ru}$ RU\&SrcAuth=RRC\&SID=E1MED5f1djpZ1Po1wqX\&customers ID $=$ RRC\&mode $=$ FullRecord\&IsProductCode $=$ Yes\&Init $=$ Yes\&action $=$ retrieve \&UT $=$ WOS\% 3A000413668602002

3. P. Berger, T. Luckmann, The social construction of reality (Doubleday, New York, 1966)

4. P. Blatchford, P. Kutnick, E. Baines, M. Galton, International Journal of Educational Research 39(1), 153-172 (2003)

5. C. Bonwell, J. Eison, ASHE-ERIC Higher Education Report No. 1 (The George Washington University, School of Education and Human Development, Washington, D.C, 1991) 
6. E. Boyer, Scholarship reconsidered (The Carnegie foundation for the Advancement of Teaching, New York, 1990)

7. O. Džinkić, J. Milutinović, Zbornik Odseka za pedagogiju 27, 129-149 (2018)

8. M.A. Ghufron, S. Ermawati, International Journal of Instruction 11(4), 657-672 (2018)

9. R. Gillies, School Psychology International 29(3), 328-347 (2008)

10. O. Knežević-Florić, Interaktivna pedagogija. Savez pedagoških društava (Vojvodine, Novi Sad, 2006)

11. M. Mannison, W. Patton, G. Lemon, Higher Education Research \& Development 13(1), 35-48 (1994) DOI: 10.1080/0729436940130104

12. N. Michel, J.J. Cater III, O. Varela, Human Resource Development Quarterly 20(4), 397-418 (2009) http://dx.doi.org/10.1002/hrdq. 20025

13. J. Milutinović, Socijalni i kritički konstruktivizam u obrazovanju (Filozofski fakultet, Novi Sad, 2016)

14. L. Rubin, C. Hebert, College Teaching 46, 26-30 (1998)

15. R.E. Slavin, Educational Leadership 48(5), 71-81 (1991)

16. R.M. Sorrentino, E.C. Hewitt, Journal of Personality and Social Psychology 47, 884899 (1984)

17. J.L. Steele, K.S. Meredith, C. Temple, Suradničko učenje: Vodič kroz projekt (Institut Otvoreno društvo Hrvatske, Zagreb, 1998)

18. J. Stevens, R.E. Slavin, American Educational Research Journal 32(2), 321-351 (1995)

19. S. Stewart-Wingfield, G.S. Black, Journal of Education for Business 81, 119-125 (2005)

20. K.M. Tateyama-Sniezek, Exceptional Children 56(5), 426-437 (1990)

21. M. Vilotijević, N. Vilotijević, Inovacije u nastavi 27(4), 21-30 (2014) 